\title{
Associations of Apoptotic and Anti-Apoptotic Factors with Beef Quality, Histochemical Characteristics, and Palatability of Hanwoo Longissimus thoracis Muscle
}

\author{
Boin Lee $\mathbb{C}^{(\mathbb{B}}$, Jae-Yeong Kim and Young-Min Choi * ${ }^{\mathbb{C}}$
}

Citation: Lee, B.; Kim, J.-Y.; Choi, Y.-M. Associations of Apoptotic and Anti-Apoptotic Factors with Beef Quality, Histochemical

Characteristics, and Palatability of Hanwoo Longissimus thoracis Muscle. Animals 2022, 12, 467. https:/ / doi.org/10.3390/ani12040467

Academic Editor: Dorota Wojtysiak

Received: 31 December 2021

Accepted: 12 February 2022

Published: 14 February 2022

Publisher's Note: MDPI stays neutral with regard to jurisdictional claims in published maps and institutional affiliations.

Copyright: (C) 2022 by the authors. Licensee MDPI, Basel, Switzerland. This article is an open access article distributed under the terms and conditions of the Creative Commons Attribution (CC BY) license (https:// creativecommons.org/licenses/by/ $4.0 /)$.
Department of Animal Sciences and Biotechnology, Kyungpook National University, Sangju-si 37224, Korea; ananassab@knu.ac.kr (B.L.); rlarbgm10603@naver.com (J.-Y.K.)

* Correspondence: ymchoi1@knu.ac.kr; Tel.: +82-54-530-1232

Simple Summary: After the onset of muscle fiber apoptosis, various apoptotic and anti-apoptotic factors are selectively increased. These factors are directly and/or indirectly associated with tenderness variation. Given the complex relationship between the apoptosis-related molecules, more data are needed on how the expression patterns of these factors during the post-mortem period affects the palatability of beef. In this study, the combination of expression levels of apoptotic (cytochrome c and caspases) and anti-apoptotic (small heat shock proteins) factors at $45 \mathrm{~min}$ post-mortem tended to be associated with Warner-Bratzler shear force and tenderness attributes in Hanwoo steers with a lower degree of marbling. Meanwhile, levels of these molecules at $24 \mathrm{~h}$ had a somewhat limited effect on the beef tenderness. Clearly, these results demonstrate that expression levels of apoptotic and anti-apoptotic molecules at the early post-mortem period may be a relevant indicator to explain the tenderness variation in Hanwoo.

Abstract: This study compared the meat quality, histochemical traits, palatability, and expression levels of apoptotic (cytochrome $\mathrm{c}$ and caspases) and anti-apoptotic (small heat shock proteins) factors at $45 \mathrm{~min}$ and $24 \mathrm{~h}$ post-mortem of Hanwoo Longissimus thoracis muscles in groups categorized by Warner-Bratzler shear force (WBS) values to investigate the association between beef tenderness variation and apoptosis-related molecules. There were no differences in marbling scores, meat quality traits, or histochemical characteristics among the WBS groups $(p>0.05)$ indicating no significant effect on the tenderness variation in the current study. On the other hand, the low group exhibited higher levels of apoptotic and anti-apoptotic factors (except for $\alpha \beta$-crystallin) at $45 \mathrm{~min}$ post-mortem compared to the high WBS group, resulting in higher scores of tenderness attributes $(p<0.05)$. However, the level of $\alpha \beta$-crystallin at $45 \mathrm{~min}$ post-mortem was lower in the low and medium WBS groups compared to the high WBS group $(p<0.0106)$. At $24 \mathrm{~h}$ post-mortem, no significant differences were observed in the expression levels of apoptosis-related factors among the WBS groups $(p>0.05)$ except for heat shock protein $27(p<0.05)$.

Keywords: tenderness; apoptosis; caspases; cytochrome c; small heat shock proteins; Hanwoo

\section{Introduction}

Among the various eating-quality characteristics of cooked beef, tenderness is one of the primary attributes that consumers most value, as it plays an important role in determining the overall acceptance of the meat [1]. Thus, an ongoing aim of the beef industry is to ensure that the tenderness of beef, as experienced by consumers, is consistent and/or improving [2,3]. To improve beef tenderness, it is necessary to understand the biochemical and physical changes of skeletal muscle during the post-mortem period [4]. After exsanguination, muscle fiber apoptosis (a highly organized cell death program) is initiated, and the expression of various apoptotic and anti-apoptotic molecules, including calpains, 
caspases, and heat shock proteins (HSPs), is intrinsically and selectively increased [5]. Expression levels of these proteins are directly and/or indirectly associated with the degradation of myofibrillar proteins and responsible for variation in beef tenderness [1]. Among these proteins, calpain, a well-known $\mathrm{Ca}^{2+}$-dependent cysteine protease, has been most thoroughly investigated in terms of its relationship with tenderness [6,7]. However, the calpain system cannot fully explain all the variations in beef tenderness [8]; thus, additional research on the other proteins associated with cell apoptosis during the post-mortem period is needed.

Caspases, the family of cysteine aspartate-specific proteases, are responsible for proteolytic cleavage leading to apoptotic cell death in various tissues [6-8]. Fourteen caspases have been identified, and these proteases can be divided into two subgroups-initiator and executioner caspases-according to their signaling pathways [9]. Caspase-mediated apoptosis initially occurs via the release of cytochrome c, which acts as a trigger from mitochondria to the cytoplasm [10]. In the cytoplasm, elevated cytochrome c levels can activate the initiator caspases, especially caspase 9 , and activated initiators lead to increased expression levels of effector caspases, including caspases 3 and 7 [9]. Meanwhile, HSPs are also synthesized and expressed, and can play a variety of roles during apoptosis as molecular chaperones [11]. In particular, small HSPs, including $\alpha \beta$-crystallin, HSP20, and HSP27, can interfere with the recruitment of procaspases and proteolytic activation of caspases, consequently delaying the onset of apoptosis [11,12]. In contrast, these HSPs can facilitate proteolysis via endogenous proteases by stabilizing unstable proteins and inhibiting the formation of aggregated proteins [13].

Considering the complex relationship between the apoptotic and anti-apoptotic proteins, more data on the combination of their protein expression levels and on individual expression levels during the post-mortem period is required; furthermore, how these expression levels affect the palatability, especially tenderness, of beef should be investigated. Therefore, the objective of the present study was to determine the effects of cytochrome c, caspases (caspases 3, 7, and 9), and small HSPs ( $\alpha \beta$-crystallin, HSP20, and HSP27) expression levels during the post-mortem period on the meat quality, histochemical, and eating quality characteristics of Hanwoo Longissimus thoracis (LT) muscle groups according to Warner-Bratzler shear force (WBS) values. Overall, the aim was to understand the association between variation in beef tenderness and apoptosis-related proteins.

\section{Materials and Methods}

\subsection{Animals and Muscle Samples}

The Hanwoo steers were obtained at the local slaughterhouse (Hoengseong, South Korea) in eight batches (five to six steers per batch with 41 steers in total). Following the standard slaughter procedures of the Korea Institute for Animal Products Quality Evaluation (KAPE) [14], 41 LT muscles (approximately 800 to $1000 \mathrm{~g}$ per animal) were used in the present study. At 45 min post-mortem, the $\mathrm{pH}$ value of each LT muscle was measured at the same location, i.e., at 13th thoracic vertebra (the standard location for measurement of beef quality grades). Additionally, muscle samples (about 40 g per sample) were collected from the midsection of the LT muscle at the 13th thoracic vertebra, frozen by liquid nitrogen, and then stored at $-80{ }^{\circ} \mathrm{C}$ for histochemical analysis, quantitative real-time polymerase chain reaction (RT-PCR), and Western blot analysis. At $24 \mathrm{~h}$ post-mortem, a quality grading evaluation, including marbling and texture, was performed according to the carcass grading standard of the KAPE [14]. Marbling was graded on a 9-point scale (devoid to very abundant) by trained evaluators of the KAPE [14], where the loin samples used in this study had beef marbling standard scores of 1-5. After grading of the carcass quality, samples were obtained between the 9th to 13th thoracic vertebrae of the LT muscles to be used for measurements of meat quality, including WBS, and eating quality characteristics. Meat quality characteristics, including WBS, muscle $\mathrm{pH}$, meat color, and water-holding capacity, were immediately assessed in cold room $\left(4^{\circ} \mathrm{C}\right)$. The samples were then removed into steak-size cuts $(1.5 \mathrm{~cm}$ thick; about 100-120 g per sample) and were 
stored at $-20^{\circ} \mathrm{C}$ until sensory quality analysis. The intramuscular fat (IMF) content was determined using the Soxhlet method with a solvent extraction system [15].

\subsection{Meat Quality Characteristics}

At $24 \mathrm{~h}$ post-mortem, meat quality traits were measured. WBS analysis was conducted according to a previously published method [16]. Each beef sample (approximately $80 \mathrm{~g}$ ) at $24 \mathrm{~h}$ post-mortem was put into a polyethylene bag, and then heated in a temperaturecontrolled water bath $\left(80^{\circ} \mathrm{C}\right)$ until the core temperature reached $71{ }^{\circ} \mathrm{C}$ according to a spear-type thermometer (Testo 108, Testo Inc., Lenzkirch, Germany) measurement. Cooked samples were cooled in an ice-slurry until equilibration, after which at least 10 core samples (1.27 cm diameter) were produced by cutting parallel to the muscle fiber orientation. Core samples were analyzed using an Instron Universal Testing machine (Model 1011, Instron Corp., Canton, MA, USA) arraying a Warner-Bratzler blade operating at a crosshead speed of $200 \mathrm{~mm} / \mathrm{min}$.

The $\mathrm{pH}_{24}$ h of each LT muscle was measured using a portable $\mathrm{pH}$ - and temperaturemeasuring instrument with a penetration probe (Testo 206-pH2, Testo AG, Lenzkirch, Germany). After $30 \mathrm{~min}$ of blooming time at $4{ }^{\circ} \mathrm{C}$, meat surface color was assessed using a Minolta chromometer (diffuse D65; illumination C; viewing angle, $0^{\circ}$; port/viewing area, $8 \mathrm{~mm}$; CR-400, Minolta Camera Co., Osaka, Japan). Color values, including lightness $\left(L^{*}\right)$, redness $\left(a^{*}\right)$, and yellowness $\left(b^{*}\right)$, were measured according to the recommendations of the Commission Internationale de l'Eclairage [17]. To measure drip loss [16], muscle samples (initial weight of about $80 \mathrm{~g}$ ) were placed inside plastic bag in such a way as to ensure that they were not attached to the plastic bag, after which they were hung on nets in a cold room $\left(4^{\circ} \mathrm{C}\right)$ for $48 \mathrm{~h}$. Drip loss percentage was calculated as the difference in sample weight before and after $48 \mathrm{~h}$. Filter-paper fluid uptake (FFU) was measured by pre-weighing filter paper, placing it onto the meat surface for less than $2 \mathrm{~s}$ to absorb fluids, and then weighing it again [18]. The preparation of cooked meat samples for cooking loss was identical to that used for WBS analysis, and cooking loss was calculated by weighing the samples before and after cooking [16].

\subsection{Histochemical Analysis}

Serial muscle cross-sections were obtained using a cryostat (CM1860, Leica Biosystems, Wetzlar, Germany) set at $10 \mu \mathrm{m}$ thickness and $-25^{\circ} \mathrm{C}$. To measure fiber and bundle characteristics, muscle sections were stained using the myosin ATPase staining method with acid-preincubation ( $\mathrm{pH}$ 4.3). Muscle fiber types, including I, IIA, and IIX, were classified according to their contractile and metabolism characteristics [19]. Stained samples were photographed through a microscope (DM500, Leica Microsystems, Wetzlar, Germany) equipped with a high-definition digital camera (ICC50, Leica Microsystems, Milton Keynes, England). Using Image-Pro Plus software (Media Cybernetics, Silver Spring, MD, USA), the histochemical images were analyzed, and more than 600 fibers and 30 bundles were used for statistical analysis of histochemical traits. To assess fiber characteristics, mean area, total fiber number, and fiber area percentage were measured at $100 \times$ magnification. The mean fiber area was determined as the total area divided by the total number of fibers counted. Fiber density was calculated from the average fiber number per $\mathrm{mm}^{2}$ (data not shown). The total fiber number was determined by multiplying muscle fiber density by the loin-eye area. Area percentage of each fiber type was calculated as the ratio of the total area of each fiber type to the total area measured. For bundle characteristics, bundle area and fiber number per bundle were measured at $40 \times$ magnification.

\subsection{Sensory Evaluation}

A total of $41 \mathrm{LT}$ samples at $24 \mathrm{~h}$ post-mortem were randomly selected by coding with a 3-digit number and evaluated twice during 16 sessions (5-6 samples per session). The panelists (six women and five men aged 23-48 years) were trained for at least 6 months at the Muscle Biology Laboratory of Kyungpook National University (KNU 2019-0027) 
according to the guidelines of the American Meat Science Association [20]. Frozen LT samples were thawed at $4{ }^{\circ} \mathrm{C}$ for $18 \mathrm{~h}$, after which they were cooked by pan-frying using an induction electric range until their core temperature reached $71^{\circ} \mathrm{C}$ (CIR-IH300RGL, Cuchen, Cheonan, Korea). Trained panelists were provided with cooked samples $\left(1.3 \mathrm{~cm}^{3}\right.$ cubes). During the sensory evaluation, panelists were served water and non-salt crackers to refresh their mouths before and after the evaluation of each sample. The following sensory quality traits were assessed on 9-point scale (1 to 9; low to high): softness (very hard to very soft), initial tenderness (very tough to very tender), chewiness (very chewy to very tender), rate of breakdown (very slow to very fast), amount of perceptible residue (highly abundant to none), overall tenderness (dislike extremely to like extremely), juiciness (not juicy to extremely juicy), flavor intensity (very weak to very strong), off-flavor intensity (very strong to very weak), and overall acceptability (dislike extremely to like extremely).

\subsection{Quantitative RT-PCR}

Total RNA was isolated according to the manufacturer's instructions and then RNA quantity was measured using a real-time PCR instrument (ABI 7300, Applied Biosystems, CA, USA). The quality of RNA was evaluated by gel electrophoresis and normalized accordingly. One nanogram of total RNA was used to synthesize complementary DNA. Quantitative RT-PCR was used to determine the relative mRNA expression levels of CYCS (cytochrome c), CASP 9 (caspase 9), CASP 3 (caspase 3), CASP 7 (caspase 7), and GAPDH (glyceraldehyde-3-phosphate dehydrogenase) in LT muscle. The sequences of CYCS, CASP 9, CASP 3, CASP 7, and GAPDH were as follows: 5'-GAA TGG GTG TCC GCA ACG-3', 5'-TTG GCA CAA GAG CAG TCG TT-3'; 5'-TTG ACC CAT CAA AGC CGA GC-3' , 5'-ACC TCT GGT CTG AGA ACC TCA-3'; $5^{\prime}$-GAA CTT CCA CGA AAA TAC TGG CA-3', $5^{\prime}$-TCC TGA CTT CGT ATT TCA AGT TCA-3 ${ }^{\prime} ; 5^{\prime}$-GAA TGG GTG TCC GCA ACG-3', 5'-TTG GCA CAA GAG CAG TCG TT-3'; 5'-CCT GCC CGT TCG ACA GAT AG-3', and 5'-AGT GAA GAC CCC AGT GGA CT-3', respectively. Quantitative RT-PCR was performed using SYBR green dye (A25741, Applied Biosystems) and a real-time PCR instrument (ABI 7300, Applied Biosystems). Relative gene expression was calculated using the comparative $2^{-\Delta \Delta C t}$ method for relative quantification.

\subsection{Western Blot Analysis}

Muscle proteins were extracted from homogenizing LT muscles (about $0.12 \mathrm{~g}$ ) in radio immunoprecipitation assay buffer $(1.2 \mathrm{~mL})$ at $45 \mathrm{~min}$ and $24 \mathrm{~h}$ post-mortem. Proteins were quantified and normalized using Coomassie staining. Muscle proteins $(5 \mu \mathrm{L})$ were separated through 12\% SDS-PAGE gel using a Mini-PROTEAN system (Bio-Rad Laboratories Inc., Richmond, CA, USA) and then transferred to polyvinylidene difluoride membranes (GE Healthcare Ltd., Freiburg, Germany). Transferred membranes were blocked with $5 \%$ non-fat dry milk powder in Tris-buffered saline/Tween. For Western blot analysis, the following primary antibodies were used: $\alpha \beta$-crystallin (1:10,000 dilution; ab13496, Abcam Ltd., Cambridge, UK), HSP20 (1:1000 dilution; ab13491, Abcam Ltd.), and HSP27 (1:3000 dilution; sc-13132, Santa Cruz Biotechnology Inc., Santa Cruz, CA, USA). HSP27 antibody detects $27 \mathrm{kDa}$ (intact form) and $22 \mathrm{kDa}$ (degraded form) proteins. The secondary antibody used was anti-mouse immunoglobulin $\mathrm{G}(\mathrm{IgG})$ horseradish-peroxidase-linked antibody (1:3000 dilution; Cell Signaling Technology Inc., Danvers, MA, USA). A WesternBright ECL Kit (Advansta Inc., Menlo Park, CA, USA) was used to detect proteins and images were taken using the ImageQuant LAS 500 (GE Healthcare Ltd., Freiburg, Germany). Each protein band was analyzed using one-dimensional image analysis software (Eastman Kodak Co., Rochester, NY, USA).

\subsection{Statistical Analysis}

The FASTCLUS procedure (SAS Institute, NC, USA) was performed to generate three clusters based on WBS values (low, $\mathrm{n}=14$; medium, $\mathrm{n}=14$; high, $\mathrm{n}=13$ ). Regarding WBS values, meat quality traits, histochemical traits, and the expression levels of cytochrome $\mathrm{c}$, 
caspases, and small HSPs, a general linear mixed model (GLM) procedure was conducted to elucidate any associations. Regarding the sensory quality characteristics, a GLM was produced by analyzing the WBS value as a fixed effect and the trained panelists as a random effect. Significant differences in the least-square means (LSMs) for investigated parameters between the groups were compared through the probability difference option at $p<0.05$. All data are presented as LSMs with standard errors.

\section{Results}

\subsection{Comparison of Meat Quality and Histochemical Characteristics}

As expected, a marked difference was detected in the WBS values of the LT muscle among the groups (Table 1); the WBS values were appropriately higher in the order of the high, medium, and low groups (67.4 vs. 58.9 vs. $50.9 \mathrm{~N}, p<0.0001)$. No differences were observed in the marbling score and IMF content among these groups $(p>0.05)$, and similar texture and firmness scores, as measured by trained carcass evaluators, were observed among the groups (data not shown, $p>0.05$ ). Regarding the meat quality traits, beef samples did not differ in terms of muscle $\mathrm{pH}$ at $45 \mathrm{~min}$ and $24 \mathrm{~h}$ post-mortem among the groups $(p>0.05)$. Measured lightness, redness, and yellowness values were similar among the groups $(p>0.05)$. Additionally, the WBS value groups exhibited no differences in water-holding capacity parameters, including drip loss, FFU, and cooking loss $(p>0.05)$.

Table 1. Comparison of meat quality traits of the Hanwoo Longissimus thoracis muscle in groups categorized according to Warner-Bratzler shear force (WBS) values.

\begin{tabular}{|c|c|c|c|c|}
\hline & \multicolumn{3}{|c|}{ WBS Value Group } & \multirow[b]{2}{*}{$p$-Value } \\
\hline & $\begin{array}{c}\text { Low } \\
(n=14)\end{array}$ & $\begin{array}{c}\text { Medium } \\
(n=14)\end{array}$ & $\begin{array}{c}\text { High } \\
(n=13)\end{array}$ & \\
\hline WBS (N) & $50.9^{\mathrm{c}}(0.94)^{1}$ & $58.9^{b}(0.94)$ & $67.4^{\mathrm{a}}(1.06)$ & $<0.0001$ \\
\hline Marbling score & $3.93(0.32)$ & $3.79(0.32)$ & $3.67(0.34)$ & 0.9082 \\
\hline IMF content $(\%)$ & $7.98(1.63)$ & $9.27(1.63)$ & $9.12(1.63)$ & 0.7642 \\
\hline Muscle $\mathrm{pH}_{45} \min$ & $6.14(0.09)$ & $6.22(0.09)$ & $6.12(0.09)$ & 0.7893 \\
\hline Muscle $\mathrm{pH}_{24 \mathrm{~h}}$ & $5.45(0.04)$ & $5.56(0.04)$ & $5.45(0.04)$ & 0.1467 \\
\hline Lightness $\left(L^{*}\right)$ & $29.9(1.07)$ & $30.0(1.07)$ & $28.2(1.16)$ & 0.8546 \\
\hline Redness $\left(a^{*}\right)$ & $16.1(0.78)$ & $16.3(0.78)$ & $9.06(1.45)$ & 0.9596 \\
\hline Yellowness $\left(b^{*}\right)$ & $7.52(1.34)$ & $7.71(1.34)$ & $9.06(1.45)$ & 0.6560 \\
\hline Drip loss (\%) & $1.07(0.16)$ & $0.99(0.16)$ & $0.80(0.17)$ & 0.3913 \\
\hline FFU (mg) & $3.12(1.11)$ & $3.11(1.11)$ & $5.57(1.19)$ & 0.9995 \\
\hline Cooking loss (\%) & $22.6(2.42)$ & $23.6(2.42)$ & $25.1(2.61)$ & 0.4044 \\
\hline
\end{tabular}

${ }^{\mathrm{a}-\mathrm{c}}$ Different superscript letters in the same row represent significant differences $(p<0.05) .{ }^{1}$ Standard error of the mean. Abbreviations: IMF, intramuscular fat; FFU, filter-paper fluid uptake.

There were no significant differences in fiber area, total fiber number, or fiber composition among the groups (Table $2 ; p>0.05$ ). Moreover, the mean area and fiber number per bundle did not differ significantly among the groups $(p>0.05)$.

\subsection{Comparison of Eating Quality Characteristics}

All tenderness attributes differed significantly between the low and high groups (Table 3; $p$ <.05). Higher scores for softness (6.02 vs. 5.20, $p=0.0012$ ) and initial tenderness (5.92 vs. 5.00, $p=0.0016$ ) were observed when comparing the low group to the medium group; however, there was no difference in these scores between the medium and high groups $(p>0.05)$. The medium group also had similar scores for chewiness, rate of breakdown, and amount of perceptible residue relative to the scores for the other groups $(p>0.05)$, whereas significantly lower scores for these traits were observed for the high group relative to the scores recorded for the low group $(p<0.05)$. Like softness, the low group had a higher acceptability of overall tenderness compared to the medium and high groups (5.78 vs. 4.94 and $4.47, p=0.0037$ ). No differences were observed in juiciness, flavor intensity, or off-flavor intensity among the groups $(p>0.05)$. LT steaks from the low group 
showed a higher overall acceptability compared to LT steaks from the medium and high groups (5.71 vs. 4.93 and $4.49, p=0.0065)$.

Table 2. Comparison of muscle fiber and bundle characteristics of the Hanwoo Longissimus thoracis muscle in groups categorized according to Warner-Bratzler shear force (WBS) values.

\begin{tabular}{ccccc}
\hline & \multicolumn{3}{c}{ WBS Value Group } & \multirow{2}{*}{$p$-Value } \\
\cline { 2 - 4 } & Low & Medium & High & \\
\hline Muscle fiber area $\left(\mu \mathrm{m}^{2}\right)$ & $4030(236)^{1}$ & $3995(236)$ & $4190(226)$ & 0.8304 \\
Total fiber number $(\times 1000)$ & $2444(185)$ & $2335(185)$ & $2363(151)$ & 0.8896 \\
\hline Fiber area percentage $(\%)$ & & & & \\
Type I & $24.8(1.65)$ & $19.4(1.65)$ & $22.4(1.34)$ & 0.0610 \\
Type IIA & $23.7(2.42)$ & $25.2(2.42)$ & $25.7(1.98)$ & 0.7780 \\
Type IIX & $51.4(2.60)$ & $55.3(2.60)$ & $51.8(2.13)$ & 0.4837 \\
\hline Muscle bundle characteristics & & & & \\
Bundle area $\left(m^{2}\right)$ & $0.37(0.03)$ & $0.36(0.03)$ & $0.42(0.03)$ & 0.3117 \\
Fiber number per bundle & $92.8(12.2)$ & $97.3(12.2)$ & $107(9.96)$ & 0.6051 \\
\hline
\end{tabular}

${ }^{1}$ Standard error of the mean.

Table 3. Comparison of sensory quality characteristics of the Hanwoo Longissimus thoracis muscle in groups categorized according to Warner-Bratzler shear force (WBS) values.

\begin{tabular}{ccccc}
\hline & \multicolumn{3}{c}{ WBS Value Group } & \multirow{2}{*}{$p$-Value } \\
\cline { 2 - 4 } & Low & Medium & High & \\
\cline { 2 - 4 } Softness & $6.02^{\mathrm{a}}(0.23)^{1}$ & $5.20^{\mathrm{b}}(0.23)$ & $4.67^{\mathrm{c}}(0.25)$ & 0.0012 \\
Initial tenderness & $5.92^{\mathrm{a}}(0.24)$ & $5.00^{\mathrm{b}}(0.24)$ & $4.55^{\mathrm{b}}(0.26)$ & 0.0016 \\
Chewiness & $5.59^{\mathrm{a}}(0.25)$ & $4.90^{\mathrm{ab}}(0.25)$ & $4.24^{\mathrm{b}}(0.26)$ & 0.0038 \\
Rate of breakdown & $5.50^{\mathrm{a}}(0.22)$ & $4.96^{\mathrm{ab}}(0.22)$ & $4.60^{\mathrm{b}}(0.24)$ & 0.0315 \\
Amount of & $5.68^{\mathrm{a}}(0.21)$ & $5.14^{\mathrm{ab}}(0.21)$ & $4.91^{\mathrm{b}}(0.22)$ & 0.0429 \\
perceptible residue & $5.78^{\mathrm{a}}(0.25)$ & $4.94^{\mathrm{b}}(0.25)$ & $4.47^{\mathrm{b}}(0.27)$ & 0.0037 \\
Overall tenderness & $5.19^{(0.21)}$ & $4.89(0.21)$ & $4.67(0.22)$ & 0.2365 \\
Juiciness & $5.62^{(0.14)}$ & $5.66(0.14)$ & $5.49(0.15)$ & 0.7169 \\
Flavor intensity & $6.36^{(0.18)}$ & $6.36(0.18)$ & $6.03(0.19)$ & 0.3641 \\
Off-flavor intensity & $5.71^{\mathrm{a}}(0.25)$ & $4.93^{\mathrm{b}}(0.25)$ & $4.49^{\mathrm{b}}(0.27)$ & 0.0065 \\
Overall acceptability &
\end{tabular}

$\overline{\mathrm{a}-\mathrm{c}}$ Different superscript letters in the same row represent significant differences $(p<0.05) .{ }^{1}$ Standard error of the mean.

\subsection{Comparison of Apoptotic and Anti-Apoptotic Factors}

At $45 \mathrm{~min}$ post-mortem, higher levels of the apoptotic factors, including cytochrome $\mathrm{c}$ and caspases 9, 3, and 7, were observed in the low group compared to the medium and high groups (Figure $1 ; p<0.05$ ), whereas such differences were not detected between the medium and high groups $(p>0.05)$. The high group showed a higher level of $\alpha \beta$-crystallin compared with the levels detected in the low and medium groups ( $2.13 \mathrm{vs.} 1.00$ and 1.32, $p<0.0106)$; whereas, the high group had a lower level of HSP20 compared to the other groups $(p<0.0003)$. Higher expression levels of intact HSP27 were detected in the low group compared with levels in the high group (1.00 vs. $0.58, p<0.0286)$, however, the levels of degraded HSP27 were similar among the WBS value groups $(p>0.9803)$.

At $24 \mathrm{~h}$ post-mortem, the levels of all apoptotic factors were similar among the groups $(p>0.05$; Figure 2). Unlike at $45 \mathrm{~min}$ post-mortem, similar levels of $\alpha \beta$-crystallin and HSP20 were detected among the WBS value groups $(p>0.05)$. However, the low group exhibited a lower level of intact HSP27 compared with that in the high group $(p<0.0122)$, although similar levels of degraded HSP27 were observed in the low and high groups $(p>0.05)$. 


\section{Apoptotic factors}
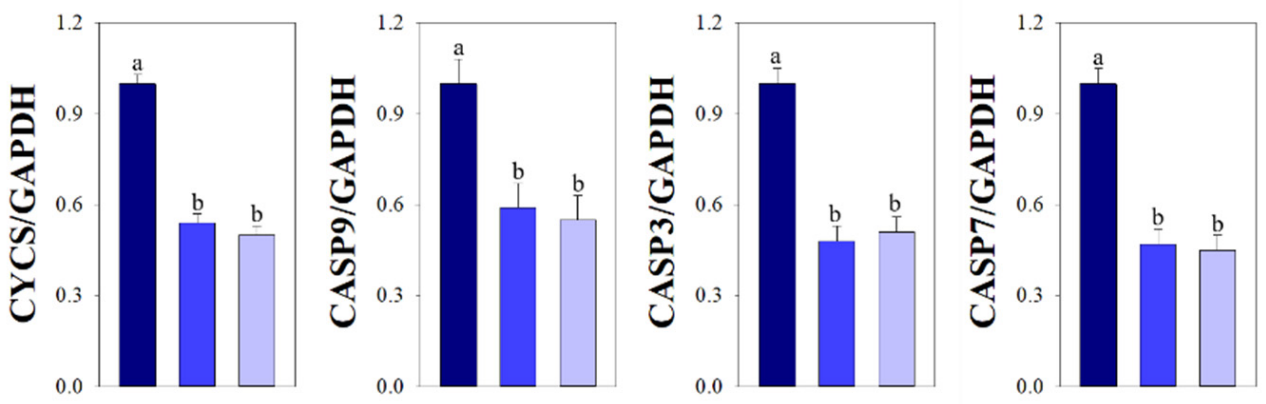

\section{Anti-apoptotic factors}
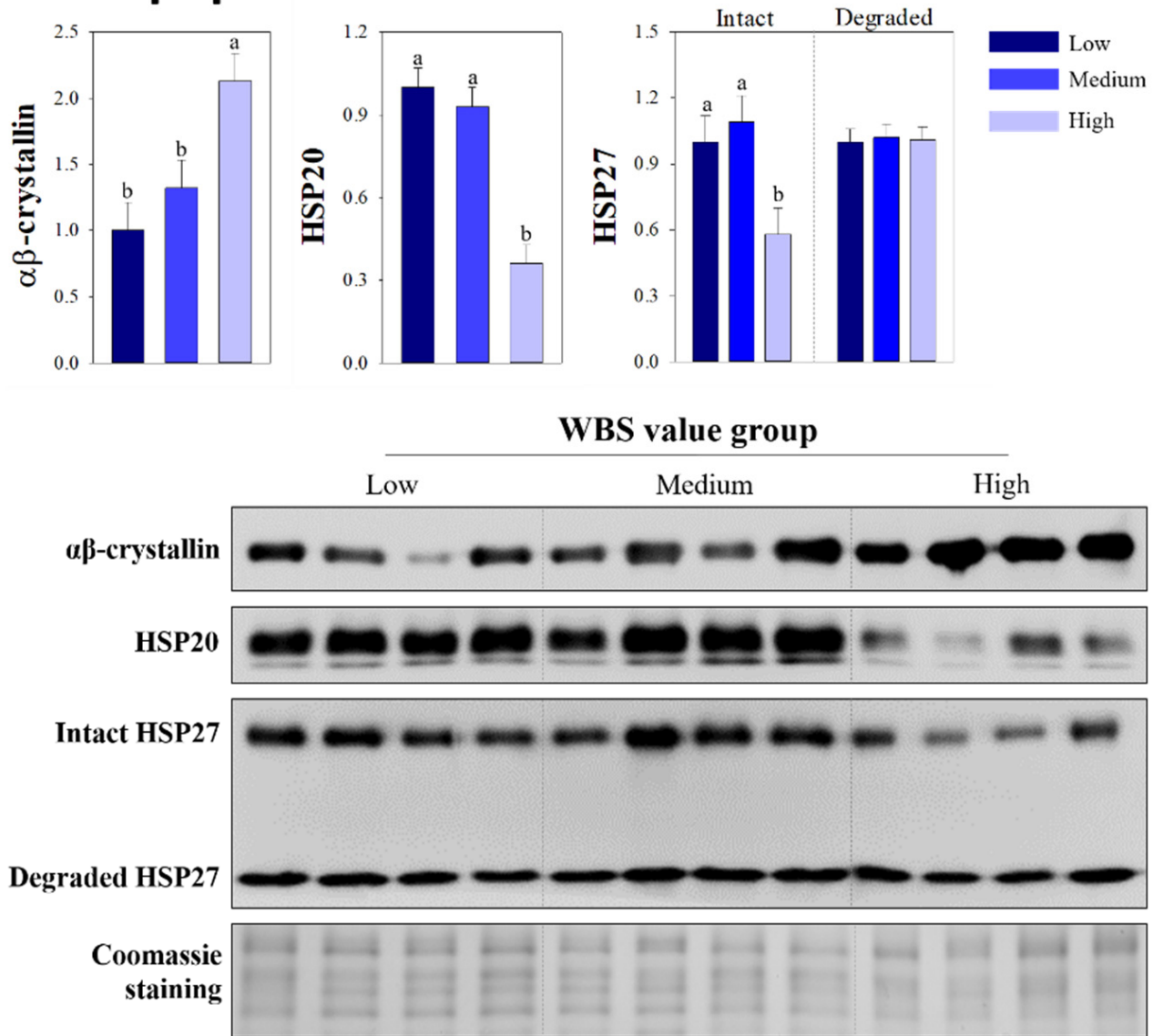

Figure 1. Quantitative RT-PCR for expression of cytochrome c (CYCS), caspase 9 (CASP 9), caspase 3 (CASP 3), and caspase 7 (CASP 7), and the relative intensities and Western blot images of the indicated heat shock proteins (HSPs) in the Hanwoo Longissimus thoracis muscle at $45 \mathrm{~min}$ post-mortem for groups categorized by Warner-Bratzler shear force (WBS) values. Gels stained by Coomassie blue were used as protein loading controls. Bars indicate the standard error of the mean. ${ }^{a, b}$ Different letters denote significant differences $(p<0.05)$. 


\section{Apoptotic factors}
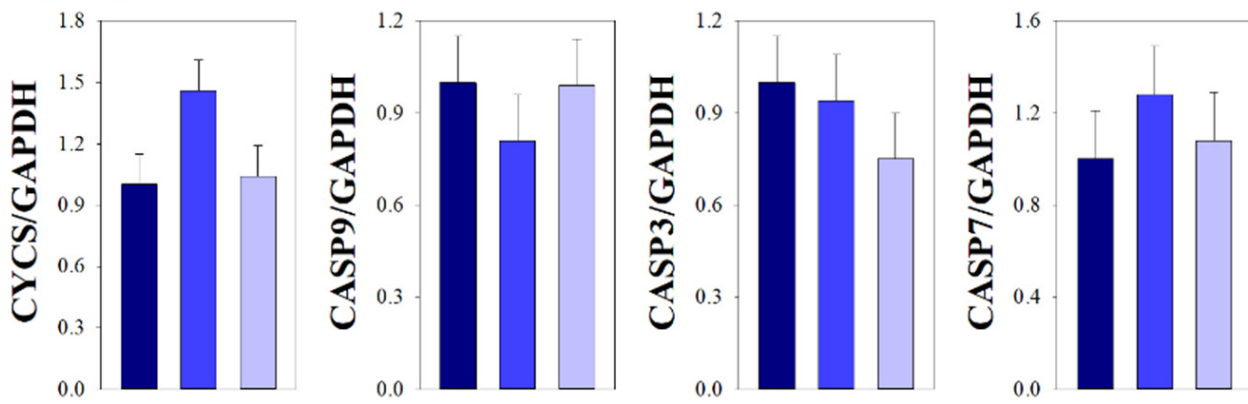

\section{Anti-apoptotic factors}
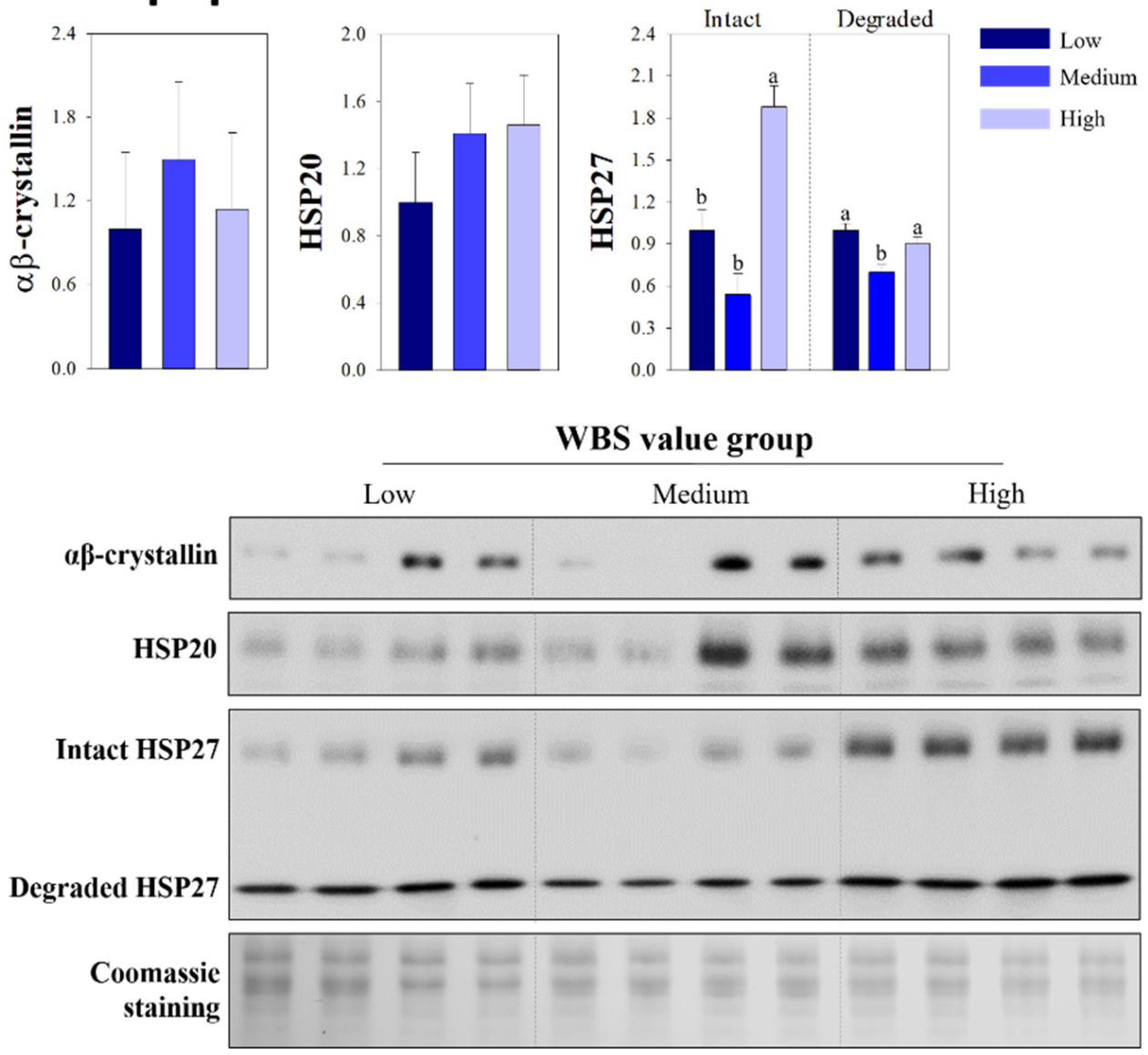

Figure 2. Quantitative RT-PCR for expression of cytochrome c (CYCS), caspase 9 (CASP 9), caspase 3 (CASP 3), and caspase 7 (CASP 7), and the relative intensities and Western blot images of the indicated heat shock proteins (HSPs) in the Hanwoo Longissimus thoracis muscle at $24 \mathrm{~h}$ post-mortem for groups categorized by Warner-Bratzler shear force (WBS) values. Gels stained by Coomassie blue were used as protein loading controls. Bars indicate the standard error of the mean. ${ }^{\mathrm{a}, \mathrm{b}}$ Different letters denote significant differences $(p<0.05)$.

\section{Discussion}

The tenderness of beef steers is substantially important to consumer acceptance and satisfaction [21]. Tenderness is known to vary due to several intrinsic and extrinsic factors [22]; it is commonly related to the characteristics of the major components of skeletal muscle including the connective tissue, IMF, and histochemical characteristics [23]. Numerous studies have reported negative correlations between WBS values and the degree of marbling, which is an integral part of beef grade assessment, since the IMF content can be associated with the textural properties (especially hardness) and water retention of cooked 
beef $[24,25]$. Previously, Choi et al. [26] confirmed that muscle fiber bundle traits can affect the texture and firmness of muscle surface. Moreover, the WBS values are positively related to the bundle size or fiber number per bundle in Hanwoo LT muscle [23,27], and showed a strong negative correlation with tenderness attributes performed by trained panelists [26]. In the present study, the WBS values of all groups tended to be higher as the degree of marbling was lower than that of highly marbled beef in the previous study [23]. The WBS groups classified by cluster analysis did not differ in terms of marbling and texture scores; these groups were also similar in their meat quality and histochemical characteristics, including bundle traits. In contrast, significant differences were observed in the tenderness attributes, as assessed by trained panelists, of the low and high WBS groups, although the panelists did not recognize any differences in juiciness or flavor intensity between the two groups. These results suggest that the WBS value and tenderness variation in LT muscle samples at $24 \mathrm{~h}$ post-mortem were not caused by the degree of marbling or histochemical traits; indeed, this variation seems to be more related to other biochemical factors that affect tenderness in this study.

During the slaughtering and exsanguination processes, the skeletal muscle of livestock is deprived of oxygen and the muscle cells become ischemic [28]. Various biochemical and structural changes occur in the process of muscle conversion into meat including mitochondrial disruption, an end to ATP production, cytoplasmic acidification, and calcium deregulation in the cells [28]. These biochemical changes make cells prone to undergoing programmed cell death [29]. The activation of apoptosis proceeds according to an intrinsic or extrinsic pathway [30]; Ouali et al. [7] reported that apoptosis that manifests under ischemic conditions is activated via an intrinsic pathway. This cell apoptosis process is a mitochondrion-centered cell death that mediates outer membrane permeability and reduction in the inner transmembrane potential of mitochondria [9]. Due to these mitochondrial changes, the release of cytochrome $\mathrm{c}$ from the mitochondrial intermembrane space to the cytosol is increased, which in turn initiates the apoptotic cascade [30]. Elevated cytosolic cytochrome $\mathrm{c}$ can then bind apoptosis protease-activating factor 1 in the presence of dATP [30], and this binding form, known as the apoptosome, is essential for the activation of initiator and effector caspases [31]. In apoptotic muscle cells, released cytochrome c and activated caspases contribute to apoptosis-associated biophysicochemical changes [5]. In post-mortem cells, as the expression of apoptotic molecules such as cytochrome $\mathrm{c}$ and caspases increases, the extent of protein degradation and loss of cytoskeletal integrity also increases [5]. For these reasons, the positive effect of caspase proteolytic system on the tenderness of cooked pork, lamb, and beef has been reported in several studies, although the other endogenous proteolytic systems, such as calpain, are also attributed to tenderness variation after completion of rigor mortis [32-35]. Meanwhile, Underwood et al. [36] reported that caspase- 3 activity did not differ between the beef steaks obtained from the low and high WBS groups. In this study, the caspase systems responsible for muscle fiber destruction during the apoptotic processes tended to be associated with the WBS variations after completion of rigor mortis. Beef steaks showing higher expression levels of apoptotic factors at the early post-mortem period exhibited significantly higher tenderness attribute values compared with those of steaks showing lower expression levels of apoptotic factors, although significant differences were not observed between the medium and high groups. Thus, expression levels of intrinsic apoptosis-related factors, including cytochrome $\mathrm{c}$ and caspases, at $45 \mathrm{~min}$ post-mortem can contribute directly and/or indirectly to the sensory tenderness attributes of Hanwoo cooked steaks.

To maintain cell homeostasis, small HSPs protect the muscle fibers against the mitochondria-mediated apoptosis by blocking the release of cytochrome c, thereby reducing apoptosome formation and inhibiting caspase activities [6]. In particular, $\alpha \beta$-crystallin prevents irreversible damage to myofibrillar proteins by proteolysis [1,29]. In the present study, this anti-apoptotic function of $\alpha \beta$-crystallin may support the observed associations between HSPs and apoptotic factors at the early post-mortem period. Specifically, compared with muscle samples from the high WBS group, muscles from the low group exhibited lower 
expression levels of $\alpha \beta$-crystallin at 45 min post-mortem, which resulted in higher levels of apoptotic factors. Thus, overexpression of $\alpha \beta$-crystallin during the post-mortem period is associated with the toughness of cooked beef. Meanwhile, anti-apoptotic molecules are known to have diverse chaperoning functions during apoptotic processes [6,37]. Other small HSPs, including HSP20 and HSP27, can not only inhibit the activities of apoptotic factors, but also stabilize and prevent the aggregation of myofibrillar proteins which decreases their susceptibility to proteolytic degradation [38]. Thus, unlike $\alpha \beta$-crystallin, the increased expression levels of these proteins during apoptosis have been associated with the improved tenderness of cooked beef [29]. Here, in Hanwoo steers with a lower degree of marbling, similar result was observed; levels of HSP20 and intact HSP27 at 45 min post-mortem were significantly higher in the low and medium WBS groups than in the high WBS group. Unlike the intact form of HSP27, differences were not observed in levels of the degraded form between the WBS groups at 45 min post-mortem. Thus, the low group showing higher scores of tenderness attributes exhibited similar levels of all anti-apoptotic factors compared to the medium group, but the low group had higher levels of all apoptotic factors contributing to enzymatic protein cleavage than the medium group. These results indicated that the apoptotic potentials at $45 \mathrm{~min}$ post-mortem were different between the two groups. The difference in apoptotic potentials between the low and medium groups, which can be explained by the combination of different levels of apoptotic factors and similar levels of anti-apoptotic factors at the early post- mortem period, was the cause of tenderness variation.

Apoptosis-associated factors show significant changes in expression and activity levels during the post-mortem period with different temporal patterns [39,40]. For apoptotic molecules, the release of cytochrome $c$ and caspases increases rapidly in the cytoplasm at the early post-mortem period [41], and small HSPs as anti-apoptotic factors are detected and show increased levels in myofibrils within $30 \mathrm{~min}$ after the onset of ischemic stress [29,38]. After the early post-mortem period, the expression levels of both apoptotic and antiapoptotic factors gradually decrease, and the biological properties of these molecules are impaired during the post-mortem period [38,41]. For these reasons, the levels of apoptosisrelated proteins at $24 \mathrm{~h}$ post-mortem had a limited effect on beef tenderness variations, unlike the effects of levels of these molecules at the early post-mortem period. Indeed, with the exception of HSP27 levels, differences were not observed among the groups in terms of the levels of either apoptotic or anti-apoptotic factors at $24 \mathrm{~h}$ post-mortem. However, observed differences in the levels of HSP27 among the groups at $24 \mathrm{~h}$ post-mortem seem not to directly affect variation in tenderness. Therefore, the apoptosis-mediated biochemical and physical changes that are associated with tenderness variation are mainly influenced by the expression levels of apoptotic and anti-apoptotic proteins at the early post-mortem period rather than during other periods.

\section{Conclusions}

Overall, the marked difference in the WBS values of cooked Hanwoo beef among the WBS groups was associated with expression levels of apoptotic and anti-apoptotic factors. Increased expression of apoptotic factors and decreased expression of anti-apoptotic factors at $45 \mathrm{~min}$ post-mortem was accompanied by a greater score of sensory tenderness in the low WBS group compared to the high WBS group. Moreover, the difference in the tenderness scores of cooked beef between the low and medium groups could be explained by the different apoptotic potentials at $45 \mathrm{~min}$ post-mortem. Thus, these molecules are particularly involved in the initial step of tenderization. Consequently, the levels of apoptosis-related molecules detected during the early post-mortem period could be considered relevant indicators that explain the tenderness variation in the Hanwoo LT muscles that have similar marbling scores and texture features.

Author Contributions: Conceptualization, B.L. and Y.-M.C.; methodology, B.L.; software, B.L. and Y.-M.C.; validation, Y.-M.C.; formal analysis, B.L., J.-Y.K. and Y.-M.C.; investigation, B.L. and Y.-M.C.; resources, Y.-M.C.; data curation, J.-Y.K. and Y.-M.C.; writing-original draft preparation, B.L., 
J.-Y.K. and Y.-M.C.; visualization, B.L.; supervision, Y.-M.C.; project administration, Y.-M.C.; funding acquisition, Y.-M.C. All authors have read and agreed to the published version of the manuscript.

Funding: This research was funded by the National Research Foundation of Korea (NRF2017R1D1A3B03029840) and the Basic Science Research Program through the NRF funded by the Ministry of Education (NRF-2020R1A6A3A13053322).

Institutional Review Board Statement: The study was approved by the Bioethics Committee of Kyungpook National University (protocol number 2019-0027).

Informed Consent Statement: Not applicable.

Acknowledgments: The authors thank the KAPE for their help in the muscle sample collection and quality grading information.

Conflicts of Interest: The authors declare no conflict of interest.

\section{References}

1. Ma, D.; Kim, Y.H.B. Proteolytic changes of myofibrillar and small heat shock proteins in different bovine muscles during aging: Their relevance to tenderness and water-holding capacity. Meat Sci. 2020, 163, 108090. [CrossRef] [PubMed]

2. Hocquette, J.F.; Ellies-Oury, M.P.; Legrand, I.; Pethick, D.; Gardner, G.; Wierzbicki, J.; Polkinghorne, R. Research in beef tenderness and palatability in the Era of big data. Meat Muscle Biol. 2020, 4, 1-13. [CrossRef]

3. Picard, B.; Gagaoua, M. Proteomic investigations of beef tenderness. In Protemoics in Food Science: From Farm to Fork; Colgrave, M., Ed.; Elsevier and Academic Press: London, UK, 2017; pp. 177-196.

4. $\quad$ Bhat, Z.F.; Morton, J.D.; Mason, S.L.; Bekhit, A.E.D.A. Role of caplain system in meat tenderness: A review. Food Sci. Hum. Wellness 2018, 7, 196-204. [CrossRef]

5. Garcia-Macia, M.; Sierra, V.; Palanca, A.; Vega-Naredo, I.; De Gonzalo-Calvo, D.; Rodriguez-Gonzalez, S.; Olivan, M.; Coto-Montes, A. Autophagy during beef aging. Authophagy 2014, 10, 137-143. [CrossRef]

6. Kemp, C.M.; Parr, T. Advances in apoptotic mediated proteolysis in meat tenderization. Meat Sci. 2012, 92, 252-259. [CrossRef]

7. Ouali, A.; Herrera-Mendez, C.H.; Coulis, G.; Becila, S.; Boudjellal, A.; Aubry, L.; Sentandreu, M.A. Revisiting the conversion of muscle into meat and the underlying mechanisms. Meat Sci. 2006, 74, 44-58. [CrossRef]

8. Huang, F.; Huang, M.; Zhou, G.; Xu, X.; Xue, M. In vitro proteolysis of myofibrillar proteins from beef skeletal muscle by caspase-3 and caspase-6. J. Agric. Food Chem. 2011, 59, 9658-9663. [CrossRef]

9. Brentnall, M.; Rodriguez-Menocal, L.; De Guevara, R.L.; Cepero, E.; Boise, L.H. Caspase-9, caspase-3 and caspase-7 have distinct roles during intrinsic apoptosis. BMC Cell Biol. 2013, 14, 32. [CrossRef]

10. Cao, J.; Zhou, G.; Liu, Y.; Zhang, Q.; Ye, K.; Pan, D.; Ou, C. Activation of caspase-9 and its influencing factors in beef during conditioning. Animal 2014, 8, 504-509. [CrossRef]

11. Kamradt, M.C.; Chen, F.; Cryns, V. The small heat shock protein $\alpha$ B-crystallin negatively regulates cytochrome $c$ - and caspase-8dependent activation of caspase-3 by inhibiting its autoproteolytic maturation. J. Biol. Chem. 2001, 276, 16059-16063. [CrossRef]

12. Gopal-Srivastava, R.; Piatigorsky, J. The murine alpha B-crystallin/small heat shock protein enhancer: Identification of alpha BE-1, alpha BE-2, alpha BE-3, and MRF control elements. Mol. Cell. Biol. 1993, 13, 7144-7152. [PubMed]

13. Waters, E.R.; Lee, G.J.; Vierling, E. Evolution, structure and function of the small heat shock proteins in plants. J. Exp. Bot. 1996, 47, 325-338. [CrossRef]

14. Korea Institute of Animal Products Quality Evaluation (KAPE). The Beef Carcass Grading. Available online: http:/ /www.ekape. or.kr/index.do (accessed on 1 June 2020).

15. AOAC International. Official Methods of Analysis of AOAC International, 19th ed.; AOAC International: Gaithersburg, MD, USA, 2006.

16. Honikel, K.O. Reference methods for the assessment of physical characteristics of meat. Meat Sci. 1998, 49, 447-457. [CrossRef]

17. Commission Internationale de l'Eclairage (CIE). Recommendations on Uniform Color Spaces-Color Differences Equations, Psychrometic Color Terms; Central Bureau of the Commission Internationale de l'Eclairage: Vienna, Austria, 1978.

18. Kauffman, R.G.; Eikelenboom, G.; Van der Wal, P.G.; Merkus, G.; Zaar, M. The use of filter paper to estimate drip loss of porcine musculature. Meat Sci. 1986, 18, 191-200. [CrossRef]

19. Brooke, M.H.; Kaiser, K.K. Three "myosin adenosine triphosphatase" systems: The nature of their pH lability and sulfhydryl dependence. J. Histochem. Cytochem. 1970, 18, 670-672. [CrossRef]

20. American Meat Science Association. Research Guideline for Cookery, Sensory Evaluation, and Instrumental Tenderness Measurements of Fresh Meat, 2nd ed.; American Meat Science Association: Champaign, IL, USA, 2015.

21. Miller, M.F.; Carr, M.A.; Ramsey, C.B.; Crockett, K.L.; Hoover, L.C. Consumer thresholds for establishing the value of beef tenderness. J. Anim. Sci. 2001, 79, 3062-3068. [CrossRef]

22. Hopkins, D.L. The Eating Quality of Meat: II-Tenderness. In Lawrie's Meat Science, 8th ed.; Woodhead Publishing: Cambridge, UK, 2017. 
23. Lee, Y.; Lee, B.; Kim, H.K.; Yun, Y.K.; Kang, S.J.; Kim, K.T.; Kim, B.D.; Kim, E.J.; Choi, Y.M. Sensory quality characteristics with different beef quality grades and surface texture features assessed by dented area and firmness, and the relation to muscle fiber and bundle characteristics. Meat Sci. 2018, 145, 195-201. [CrossRef]

24. Hocquette, J.F.; Gondret, F.; Baeza, E.; Medale, F.; Jurie, C.; Pethick, D.W. Intramuscular fat content in meat-producing animals: Development, genetic and nutritional control, and identification of putative markers. Animal 2010, 4, 309-319. [CrossRef]

25. Lee, B.; Choi, Y.M. Correlations of marbling characteristics with meat quality and histochemical characteristics in longissimus thoracis muscle of Hanwoo steers. Food Sci. Anim. Resour. 2019, 39, 151-161. [CrossRef]

26. Choi, Y.M.; Garcia, L.G.; Lee, K. Correlation of sensory quality characteristics with intramuscular fat content and bundle characteristics in bovine longissimus thoracis muscle. Food Sci. Anim. Resour. 2019, 39, 197-208. [CrossRef]

27. Kim, J.Y.; Lee, B.; Kim, D.H.; Lee, K.; Kim, E.J.; Choi, Y.M. Sensory quality and histochemical characteristics of longissimus thoracis muscle between Hanwoo and Holstein steers of different quality grades. Food Sci. Anim. Resour. 2021, 41, 779-787. [CrossRef] [PubMed]

28. Sierra, V.; Olivan, M. Role of mitochondria on muscle cell death and meat tenderization. Recent. Pat. Endocr. Metab. Immune Drug Discov. 2013, 7, 120-129. [CrossRef] [PubMed]

29. Oh, E.; Lee, B.; Choi, Y.M. Associations of heat-shock protein expression with meat quality and sensory quality characteristics in highly marbled longissimus thoracis muscle from Hanwoo steers categorized by Warner-Bratzler shear force value. Foods 2019, 8, 638. [CrossRef] [PubMed]

30. Concannon, C.G.; Gorman, A.M.; Samali, A. On the role of Hsp27 in regulating apoptosis. Apoptosis 2003, 8, 61-70. [CrossRef]

31. Boatright, K.M.; Salvesen, G.S. Mechanisms of caspase activation. Curr. Opin. Cell Biol. 2003, 15, 725-731. [CrossRef]

32. Cramer, T.; Penick, M.L.; Waddell, J.N.; Bidwell, C.A.; Kim, Y.H.B. A new insight into meat toughness of callipyge lamb loins-The relevance of anti-apoptotic systems to decreased proteolysis. Meat Sci. 2018, 140, 66-71. [CrossRef]

33. Laville, E.; Sayd, T.; Morzel, M.; Blinet, S.; Chambon, C.; Lepetit, J.; Renand, G.; Hocquette, J.F. Proteome changes during meat aging in tough and tender beef suggest the importance of apoptosis and protein solubility for beef aging and tenderization. $J$. Agric. Food Chem. 2009, 57, 10755-10764. [CrossRef]

34. Zhang, J.; Ma, D.; Kim, Y.H.B. Mitochondrial apoptosis and proteolytic changes of myofibrillar proteins in two different pork muscles during aging. Food Chem. 2020, 319, 126571. [CrossRef]

35. Ding, Z.; Wei, Q.; Liu, C.; Zhang, H.; Huang, F. The quality changes and proteomic analysis of cattle muscle postmortem during rigor mortis. Foods 2022, 11, 217. [CrossRef]

36. Underwood, K.R.; Means, W.J.; Du, M. Caspase 3 is not likely involved in the postmortem tenderization of beef muscle. J. Anim. Sci. 2008, 86, 960-966. [CrossRef]

37. Lee, B.; Choi, Y.M. Research Note: Comparison of histochemical characteristics, chicken meat quality, and heat shock protein expressions between PSE-like condition and white-stripping features of pectoralis major muscle. Poult. Sci. 2021, 100, 10260. [CrossRef] [PubMed]

38. Lomiwes, D.; Farouk, M.M.; Wiklund, E.; Young, O.A. Small heat shock proteins and their role in meat tenderness: A review. Meat Sci. 2014, 96, 26-40. [CrossRef] [PubMed]

39. Chen, L.; Feng, X.C.; Lu, F.; Xu, X.L.; Zhou, G.H.; Li, Q.Y.; Guo, X.Y. Effects of camptothecin, etoposide and Ca2+ on caspase-3 activity and myofibrillar disruption of chicken during postmortem ageing. Meat Sci. 2011, 87, 165-174. [CrossRef] [PubMed]

40. Pulford, D.J.; Dobbie, P.; Fraga-Vazquez, S.; Fraser-Smith, E.; Frost, D.A.; Morris, C.A. Variation in bull beef quality due to ultimate muscle $\mathrm{pH}$ is correlated to endopeptidase and small heat shock protein levels. Meat Sci. 2009, 83, 1-9. [CrossRef] [PubMed]

41. Huang, F.; Huang, M.; Zhang, H.; Zhang, C.; Zhang, D.; Zhou, G. Changes in apoptotic factors and caspase activation pathways during the postmortem aging of beef muscle. Food Chem. 2016, 190, 110-114. [CrossRef] [PubMed] 